\title{
STUDI KOMPARASI: EFEKTIFITAS PSIKOEDUKASI TERHADAP ADAPTASI PASIEN FRAKTUR DI RSUD JOMBANG
}

\author{
Zuhrotul Umaroh, Program studi magister keperawatan UMY \\ e-mail:zeeka_ns@yahoo.com \\ Elsye Maria Rosa, Program studi magister keperawatan UMY \\ e-mail: elsye@umyac.id
}

\begin{abstract}
Background: The injury is still a major public health problem throughout the country, where twothirds occur in developing countries, including Indonesia. In Indonesia, recorded injury cases in 2013 reached 84,277 people (8.2\%). The negative impacts caused by the fracture appears, which includes; psychological, social, and spiritual. The Department of Health reported that $15 \%$ of patients experiencing psychological stress fractures to depression. Psychoeducation efficient in the treatment process and decrease the symptoms of depression that is a component in the psychological response on the existence of a disability condition.

Aim: the research aimed todetermine the effectiveness of psychoeducation to the physical adaptation among fracture patients in public hospital of Jombang

Method: this is a quasi-experiment research with pre-test and post-test control group design. There were 16 respondents in control group and another 16 respondents for intervention group which was gathered with consecutive sampling. The data were analyzed with parametric analysis using paired sample t-test dan independent t-test. For testing the data normality distribution, Shapiro-wilk analysis was operated.

Result: Paired t test sample stated that there was significant difference in the physical adaptation among fracture patients before and after the intervention of psychoeducation ( $p$ value $=0,000 ; C I$ $95 \%<$ alpha $=0,05)$. In the unpaired t test was obtained $p$ value $=0.000 ;$ CI 95\% <alpha $=0.05$, which indicates a significant difference of fracture patients' adaptation who has given psychoeducation intervention and who has not.

Conclusion: the psychoeducation intervention increasedphysical adaptation among fracture patients. Nurses must continue to develop and apply the procedures for implementing psychoeducation fractures primarily in patients with the aim to improve the adaptability of fracture patients.
\end{abstract}

Key Words: Fracture, Patient, Psychoeducation, Injury

\section{PENDAHULUAN}

Sampai saat ini cidera merupakan masalah kesehatan utama masyarakat di seluruh negara, Angka mortalitas oleh karena cidera ini di proyeksikan terus meningkat menjadi 8,4 juta dari awalnya sebanyak 5,1 juta dimana pada tahun 2020 diprediksi akan berada diposisi ketiga disability adjusted life years (DALYs). Di Indonesia tercatat kasus cidera pada tahun 2013 mencapai 84.277 jiwa $(8,2 \%)$ dari seluruh jumlah penduduk (Riskesdas, 2013). Berdasarkan jenis cidera, pada tahun 2013 Badan Penelitian dan Pengembangan Kesehatan melaporkan sebanyak $4.888(5,8 \%)$ jiwa mengalami patah tulang. Dimana kasus patah tulang di Indonesia masih cukup besar dan memungkinkan untuk terjadinya masalah kesehatan yang lain. Risiko infeksi dan penyembuhan tulang merupakan fase lanjutan dimana kerjasama pasien dalam perawatan dirumah sangat diperlukan agar tidak terjadi infeksi dan penyembuhan tulang berlangsung tepat waktu (Budi, 2014).

Berbagai dampak negatif muncul yang diakibatkan oleh lamanya periode proses penyembuhan pasien fraktur, yang meliputi aspek psikologis, sosial, dan spiritual. Berbagai efek tersebut muncul selama periode admisi ke rumah sakit, proses penatalaksaan operasi, setelah penatalaksanaan bedah hingga fase 
rehabilitasi. Pada 2007, Departemen Kesehatan melaporkan bahwa $15 \%$ penderita fraktur mengalami stress psikologis hingga depresi.Hal ini mengindikasikan bahwa penderita fraktur perlu mendapatkan intervensi secara holistik yang juga menyentuh aspek psikososial.

Perawat memiliki tanggung jawab yang sangat besar pada saat hari pelaksanaan operasi untuk memberikan pendidikan kesehatan pada pasien yang akan melaksanakan operasi, termasuk memberikan pendidikan tentang bagaimana memonitor gejala-gejala yang dirasakan dan mengimplementasikan perawatan diri secara mandiri (Allard, 2005). Pendidikan psikologis mengaplikasikan beberapa teknik dalam memberikan pendidikan pada pasien dalam rangka untuk memfasilitasi pengembangan kemampuan beradaptasi (koping) yang dibutuhkan untuk mengantisipasi efek negatif yang dihasilkan oleh stress, penyakit, kecelakaan ataupun disabilitas/kecacatan (Llanque, 2011).

\section{METODE PENELITIAN}

Jenis penelitian quasi eksperiment dengan desain penelitian pre-test - post-test with control group. Responden dibagi menjadi dua kelompok yaitu kelompok perlakuan yang diberikan intervensi psikoedukasi, serta kelompok kontrol yang tidak diberikan intervensi. Populasi dalam penelitian ini adalah semua pasien patah tulang derajat 2 dan 3 yang menjalani rawat inap di Rumah Sakit Umum Daerah Kabupaten Jombang. Sampel dalam penelitian didapatkan menggunakan teknik non probabilitysampling dengan pendekatan consecutive sampling dari populasi yang sudah ditentukan yang memenuhi kriteria inklusi sebagai berikut: (a) Pasien post op fraktur hari ke 1; (b) Pasien fraktur derajat 2 dan 3; (c) Berusia minimal 18 tahun; (d) Mampu berkomunikasi dengan baik; (e) Bersedia berpatisipasi dalam penelitian.Jumlah sampel terdiri dari 16 responden untuk kelompok perlakuan serta 16 responden pada kelompok kontrol.
Instrumen yang digunakan pada proses pengumpulan data menggunakan kuesioner Sickness Impact Profile (SIP) untuk mengidentifikasi status adaptasi fisik pasien fraktur derajat 2 dan 3.Kuesioner SIP telah di kembangkan oleh Bergner Marilyn dan Gilson Betty.

Kuesioner Sickness Impact Profile (SIP) yang digunakan adalah versi "intervieweradministered questionnaire", yaitu versi SIP yang dalam proses pengisiannya tidak di isi langsung oleh responden, melainkan dilakukan oleh peneliti. Peneliti (atau asisten peneliti) membacakan setiap item soal kepada responden untuk selanjutnya mendapat jawaban langsung dari responden mengenai pertanyaan yang diajukan dan peneliti mengisi jawaban pada kolom yang telah disediakan.

Penelitian ini menggunakan teknik analisa data parametrik yaitu t-test dependent (paired t-test) dan t-test independent. Uji t-test dependent digunakan untuk mengidentifikasi perbedaan mean / rata-rata pada kelompok perlakuan sebelum dan sesudah diberikan psikoedukasi serta pada kelompok kontrol pada pre-test dan post-test. Peneliti juga menggunakan teknik uji t-test independent untuk menganalisis perbedaan mean / rata-rata pada kelompok perlakuan yang telah diberikan psikoedukasi dengan kelompok kontrol.

Sebelum dilakukan uji t-test dependent, dilakukan uji normalitas data dengan menggunakan uji Saphiro-Wilk dan hasilnya menyatakan bahwa $p$-value $>$ dari alpha $=0,05$ yang berarti data berdistribusi normal.Selanjutnya dilakukan uji homogenitas dengan menggunakan Levine test dengan hasil nilai $p$-value $<0,05$ yang berarti varian data antara kelompok perlakuan dan kelompok kontrol heterogen (berbeda secara signifikan). Berdasarkan hasil uji homogenitas tersebut maka $\mathrm{p}$ uji t-test independent menggunakan formula "separate samples" (Equal variance not assumed). Proses analisa data menggunakansoftware SPSS versi 21. 
HASIL PENELITIAN DAN PEMBAHASAN

Tabel 1.Distribusi Usia responden

\begin{tabular}{|c|c|c|c|}
\hline \multicolumn{1}{|c|}{ Usia (tahun) } & Mean \pm SD & Min & Max \\
\hline Kelompok Perlakuan $(\mathrm{n}=16)$ & $37,19 \pm 1,51$ & 18 & 61 \\
\hline Kelompok Kontrol $(\mathrm{n}=16)$ & $40,44 \pm 1,73$ & 18 & 60 \\
\hline
\end{tabular}

Berdasarkan tabel 1 diatas menunjukkan bahwa rata-rata usia responden kelompok perlakuan lebih muda tiga tahun dari pada kelompok kontrol. Sebagaimana telah dijelaskan sebelumnya, usia dapat mempengaruhi tingkat stres pada pasien fraktur. Menurut Prayitno (2006) usia muda cenderung memiliki tingkat stres lebih tinggi karena pada usia muda seperti Tabel 2. Gambaran karakteristik responden usia remaja, masih menyesuaikan diri dengan standar kelompok selain itu pada usia remaja adanya perubahan yang terjadi pada dirinya seperti terjadinya fraktur akanada ketakutan adanya penolakan oleh lingkungan. Dan pada usia remaja individu belum dapat mengontrol emosinya sehingga individu belum dapat menghadapi perubahan yang terjadi.

\begin{tabular}{|c|c|c|c|c|c|c|}
\hline \multirow[b]{2}{*}{ Yariabel } & \multicolumn{2}{|c|}{$\begin{array}{l}\text { Kelompok } \\
\text { Perlakuan }\end{array}$} & \multicolumn{2}{|c|}{$\begin{array}{l}\text { Kelompol } \\
\text { Kontrol }\end{array}$} & \multicolumn{2}{|c|}{ Total } \\
\hline & Jumlah & $\begin{array}{c}\text { Persen } \\
(\%)\end{array}$ & Jumlah & $\begin{array}{c}\text { Persen } \\
\text { (\%) }\end{array}$ & Total & $\begin{array}{l}\text { Persen } \\
(\%)\end{array}$ \\
\hline Jenis Kelamin & & & & & & \\
\hline Laki-1aki & 14 & 87.5 & 12 & 75 & 26 & 81,3 \\
\hline Perempuan & 2 & 12.5 & 4 & 25 & 6 & 18,7 \\
\hline Total & 16 & $100 \%$ & 16 & $100 \%$ & 32 & $100 \%$ \\
\hline Pendidikan & & & & & & \\
\hline Tidak Tamat SD & 1 & 6,2 & 1 & 6,2 & 2 & 6,3 \\
\hline SD & 3 & 18,8 & 1 & 6,2 & 4 & 12,5 \\
\hline SMP & 1 & 6,2 & 3 & 18,8 & 4 & 12,5 \\
\hline SMA & 11 & 68,2 & 10 & 62,5 & 21 & 65,6 \\
\hline PT & 0 & 0 & 1 & 6,2 & 1 & 3,1 \\
\hline Total & 16 & $100 \%$ & 16 & $100 \%$ & 32 & $100 \%$ \\
\hline Pekerjaan & & & & & & \\
\hline Wiraswasta & 8 & 50 & 7 & 43,8 & 15 & 46,9 \\
\hline Guru & 0 & 0 & 1 & 6,2 & 1 & 3,1 \\
\hline Pelajar & 5 & 31,2 & 3 & 18,8 & 8 & 25 \\
\hline Petani & 2 & 12,5 & 2 & 12,5 & 4 & 12,5 \\
\hline Ibu Rumah Tangga & 0 & 0 & 3 & 18,8 & 3 & 9,4 \\
\hline Lain-1ain & 1 & 6,2 & 0 & 0 & 1 & 3,1 \\
\hline Total & 16 & $100 \%$ & 16 & $100 \%$ & 32 & $100 \%$ \\
\hline Status Perkawinan & & & & & & \\
\hline Kawin & 7 & 43,8 & 9 & 56,2 & 16 & 50 \\
\hline Belum kawin & 8 & 50 & 6 & 37,5 & 14 & 43,8 \\
\hline Cerai/Landa/Duda & 1 & 6,2 & 1 & 6,2 & 2 & 6,7 \\
\hline Total & 16 & $100 \%$ & 16 & $100 \%$ & 32 & $100 \%$ \\
\hline
\end{tabular}

Tabel 2. diatas menunjukkan sebagian besar responden berjenis kelamin laki-laki baik untuk kelompok perlakuan dan kelompok kontrol yaitu sejumlah 26 orang $(81,3 \%)$. Berdasarkan tingkat pendidikan, distribusi responden menunjukkan mayoritas responden berpendidikan tingkat SMA yaitu sejumlah 11 orang pada kelompok perlakuan dan sebanyak 10 orang pada kelompok kontrol.
Pekerjaan responden menunjukkan sebagian besar responden berwiraswasta pada kedua kelompok dengan persentase 46,9\%. Terdapat distribusi yang relatif seimbang pada kedua kelompok responden berdasarkan status perkawinan, yaitu pada kategori kawin dan belum kawin. 
Tabel3.Hasil Uji t-test dependent

\begin{tabular}{|c|c|c|c|c|c|c|c|c|}
\hline \multirow{2}{*}{ No } & \multirow{2}{*}{ Variabel } & \multirow{2}{*}{ Test } & \multirow{2}{*}{$\mathrm{n}$} & \multirow{2}{*}{ Mean $\pm S D$} & \multirow{2}{*}{$\begin{array}{c}\text { Mean } \\
\text { Difference }\end{array}$} & \multicolumn{2}{|c|}{$95 \% \mathrm{CI}$} & \multirow{2}{*}{$p$ value } \\
\hline & & & & & & Lower & Upper & \\
\hline \multirow[t]{2}{*}{1} & Adaptasi & Pre-test & 16 & $31,00=8,779$ & \multirow{2}{*}{12,62} & \multirow{2}{*}{6,628} & \multirow{2}{*}{18,622} & \multirow{2}{*}{0,000} \\
\hline & $\begin{array}{l}\text { Selompos } \\
\text { perlakuan }\end{array}$ & Post-test & 16 & $18,38=9,743$ & & & & \\
\hline \multirow[t]{2}{*}{2} & Adaptasi & Pre-test & 16 & $29,75=5,000$ & \multirow{2}{*}{1,44} & \multirow{2}{*}{0,888} & \multirow{2}{*}{1,987} & \multirow{2}{*}{0,000} \\
\hline & kontrol & Post-test & 16 & $28,31=4,868$ & & & & \\
\hline
\end{tabular}

Terdapat perubahan adaptasi fisik pasien fraktur sebelum dan sesudah pemberian psikoedukasi. Pada kelompok perlakuan, ratarata adaptasi fisik pasien fraktur mengalami penurunan sebesar 12,62 poin, sedangkan pada kelompok kontrol juga mengalami penurunan rata-rata 1,44 poin meskipun tidak diberikan intervensi psikoedukasi. Hasil penelitian menyatakan bahwa semua pasien fraktur mengalami ketidakadekuatan adaptasi fisik terhadap penyakit yang sedang diderita, dalam hal ini adalah pasien fraktur yang telah menjalani operasi bedah.

Koping yang efektif akan berdampak pada ketahanan tubuh dan penolakan tubuh terhadap serangan suatu penyakit baik fisik maupun psikososio dan spiritual. Apabila mekanisme koping yang di gunakan adaptif maka stress yang dialami juga akan semakin ringan (Mesuri, 2014). Dari hasil uji sampel $t$ berpasangan yang disajikan pada tabel 4 didapatkan informasi bahwa terdapat perbedaan yang signifikan pada adaptasi fisik pasien fraktur sebelum dan sesudah diberikan

intervensi psikoedukasi yang dibuktikan dengan nilai signifikansi $(p$ value $)=0,000$; CI 95\% $<$ alpha $=0,05$. Pada kelompok kontrol juga dilakukan pengukuran pre-test dan post-test didapatkan nilai signifikansi $(p$ value $)=0,000$; CI 95\% <alpha $=0,05$ yaitu ada perbedaan yang signifikan pada adaptasi fisik pasien fraktur pada kelompok yang tidak diberikan psikoedukasi.

Hal ini mengimplikasikan bahwa psikoedukasi mempunyai pengaruh yang kuat dalam memberikan kontribusi perubahan respon adaptasi fisik responden terhadap stressor.Psikoedukasi terbukti memberikan kontribusi terhadap peningkatan kemampuan adaptasi pasien fraktur. Calista Roy dalam Rasmun (2004) mengatakan bahwa ketika seseorang mengalami suatu proses perubahan pada fisik yang dapat disebabkan oleh fraktur maka individu akan melakukan penyesuaian atau proses adaptasi yaitu suatu upaya untuk mencapai keseimbangan terhadap kebutuhan oleh adanya stressor.

Tabel 4. Hasil iji t-test independen

\begin{tabular}{|c|c|c|c|c|c|c|}
\hline \multirow{2}{*}{ No } & \multirow{2}{*}{ Variabel } & \multirow{2}{*}{$\mathrm{T}$} & \multirow{2}{*}{ Mean Difference } & \multicolumn{2}{|c|}{$95 \% \mathrm{CI}$} & \multirow[b]{2}{*}{$p$ value } \\
\hline & & & & Lower & Upper & \\
\hline 1 & $\begin{array}{l}\text { Adaptasi pasien } \\
\text { fraktur }\end{array}$ & 3,960 & 11,188 & 5,418 & 5,174 & 0,000 \\
\hline
\end{tabular}

Hasil uji beda rata-rata adaptasi pasien fraktur yang diberikan intervensi psikoedukasi dengan kelompok pasien yang tidak diberikan intervensi menunjukkan perbedaan yang signifikan dengan $p$ value $=0,000 ;$ CI 95\% $<$ alpha $=0,05$. Berdasarkan hasil uji tersebut dapat disimpulkan bahwa Ha diterima atau Ho di tolak. Psikoedukasi mempunyai pengaruh yang lebih besar terhadap kemampuan berespon secara adaptif pada individu yang mengalami fraktur. Psikoedukasi merupakan pengembangan dan pemberian informasi dalam bentuk informasi bukan sebuah pengobatan namun pemberian informasi untuk mempengaruhi kesejahteraaan psikososial masyarakat. Dimana perlunya pengetahuan pasien dan keluarganya tentang penyakit untuk merencanakan perawatan dan pengobatan penyakitnya secara optimal (Waluyo, dkk, 2014).

Seseorang yang mengalami stres dalam menghadapi stresor yang mengancam kondisinya, membutuhkan dukungan dari lingkungan sehingga dapat mengurangi stres. Keefektifan sebuah koping dinilai apabila koping mampu menurunkan stress yang dialami 
seseorang. Pasien pasca bedah fraktur harus disiapkan dengan memberikan informasi melalui psikoedukasi sehingga individu yang mengalami fraktur mampu berespon secara adaptif terutama dengan kondisi fisiknya.

\section{KESIMPULAN}

1. Terdapat perbedaan yang bermakna adaptasi fisik pada kelompok kontrol sebelum dan sesudah perlakuan pemberian psikoedukasi pada pasien fraktur.

2. Terdapat perbedaan adaptasi fisik yang bermakna pada kelompok intervensi sebelum dan sesudah perlakuan pemberian psikoedukasi pada pasien fraktur.

3. Ada pengaruh psikoedukasi terhadap adaptasi fisik pada pasien fraktur di RSUD Jombang. Di ketahui terdapat perbedaan yang bermakna antara adaptasi fisik pada kelompok kontrol dan kelompok intervensi sesudah perlakuan psikoedukasi pada pasien fraktur.

\section{DAFTAR PUSTAKA}

Allard, N. (2005). Day Surgery And Recovery In Women With A Suspicious Breast Lesion: Evaluation Of A Psychoeducational Nursing Intervention. University of Toronto

Ambarwati, W. 2015.Efektivitas Program Psikoedukasi Kelompok dalam menurunkan Beban psikologis pada Family Caregiver Diabetes Mellitus. [serial online] http://etd.repository.ugm. ac.id/index.php [diakses pada 21 Februari 2016].

Astuti, P. (2011). Pengaruh Edukasi Preoperasi Terstruktur (Dengan Teori Kognitif Sosial) Terhadap Self-Efficacy Dan Perilaku Latihan Ost Operasi Pada Pasien Fraktur Ekstrimitas Bawah Dengan Pembedahan Di Surabaya.Depok : FIK UI

Ayu Puspita, (2012). Faktor- Faktor Yang Berhubungan Dengan Keterlambatan Berobat Pada Pasien Patah Tulang Yang Menggunakan Sistem Pembiayaan Jamkesmas.Semarang: FK UNDIP

Basford, L. 2006. Teori \& Praktek Keperawatan: Pendekatan Integral pada
Asuhan Pasien. Alih Bahasa: Agung Waluyo. Jakarta: EGC.

Brown, N W. 2011. Psychoeducational Groups 3rd Edition: Process and Practice. New York: Routledge Taylor \& Francis Group.

Cartwright, M.E. (2007). Psychoeducation among caregivers of children receiving mental health services.Dissertation.Ohio : Graduate School of The Ohio State University

Carvile K.2007. Wound Care Manual (5th ed.). Australia: Silver Chain Nursing Association.

Darsih. (2013). Efektifitas Psikoedukasi Dan Guided Imagery Terhadap Kecemasan Pasien Pre Kateterisasi Jantung Di RSUP Dr Sardjito Yogyakarta

Dowrick, et al. (2000) Problem solving treatment and group psychoeducation forDepression: multicentre randomised controlled trial.BMJ Volume 321

Dowling, M. (2005).Homeostatis and Well Being.diunduh pada 6 Juni 2013 dari http://www.economics.smu.edu.sg

Eldawati, (2011).Pengaruh Latihan Kekuatan Otot Pre Operasi Terhadap Kemampuan Ambulansi Dini Pasien Pasca Operasi Fraktur Ekstremitas Bawah Di Rsup Fatmawati Jakarta.

Girsang, B., Novalina, M., Jaji.(2015). Pengaruh Psikoedukasiterhadap Tingkat Postpartum Blues Ibu Primipara Berusia Remaja. Jurnal Keperawatan Soedirman (The Soedirman Journal of Nursing), Volume 10, No.2, Juli 2015

Hawari, D. (2011). Manajemen Stres Cemas Dan Depresi. Jakarta : FKUI.

Hidayat. (2006). Pengantar Kebutuhan Dasar Manusia: Aplikasi Konsep dan Proses Keperawatan. Jakarta. Salemba Medika.

Huriani.(2006). Kajian Metode Pengajaran Klinik dalam Meningkatkan Pencapaian Kompetensi Mahasiswa Program Studi Ilmu Keperawatan dalam Praktek Profesi Program Studi Ilmu Keperawatan Fakultas Kedokteran Universitas Andalas. Padang: Universitas Andalas

Jose,S. (2009). Effects of brief psychoeducational information on Chinese - and caucasian-american college students' beliefs Toward mental illness 
and treatment-seeking attitudes. New York : Binghamton University

Kusnanto. 2004. Pengantar Profesi Dan Praktik Keperawatan Professional. Jakarta: EGC.

Kuswita, P., Jaji. (2013) Pengaruh Psikoedukasi Terhadap Tingkat Kecemasan Pada Pasien Kanker Payudara Di Rsup Mohammad Hoesin Palembang.

Lestari, A. 2014.Pengaruh Terapi Psikoedukasi Keluarga Terhadap Pengetahuan Dan Tingkat Ansietas Keluarga Dalam Merawat Anggota Keluarga Yang Mengalami Tuberculosis Paru Di Kota Bandar Lampung.Serial online https://www.scribd.com/doc/178736232/J

URNAL-Erapipsikoedukasi diakses 27 Mei 2016].

Llanque,SM. (2011). Impact of $a$ psychoeducational intervention On dementia caregiving. Kansas City : Missouri

Long, B. C. (2006). Medical-Surgical Nursing: A Nursing Process Approach (4th ed.). St. Louis: Mosby.

Lucas Brian. (2008). Preparing Hip And Total Knee Replacement: Preoperative Nursing Management,British Journal Of Nursing, vol.17, number $21: 1346-1351$

Mansjoer, A, dkk. 2010. Kapita Selekta Kedokteran. Jakarta: Medica Aesculpalus, FKUI

Margono. (2012). Efektifitas Teknik Relaksasi Nafas Dalam Terhadap Penngkatan Adaptasi Regulator Tubuh Untuk Menurunkan Nyeri Pasien Post Operasi Fraktur Ri Rumah Sakit Orthopedic Soeharso Surakarta.

Mesuri,R.P.(2014) Hubungan Mekanisme Koping Dengan Tingkat Stress Pada Pasien Fraktur. Ners Jurnal Keperawatan volume 10, No 1, Maret 2014 : 66-74

Nasriati, R. (2015). Pengaruh Kombinasi Edukasi Nyeri Dan Meditasi Dzikir Terhadap Peningkatan Adaptasi Nyeri Pasien Pasca Operasi Fraktur.

Notoatmodjo, S. 2003. Pendidikan dan prilaku kesehatan. Jakarta: Rineka Cipta.

Notoatmodjo, S. (2007).Promosi kesehatan \& ilmu perilaku.Jakarta : Rineka Cipta

Notosoedirdjo, Moeljono, \& Latipun. 2005. Kesehatan Mental: Konsep dan
Penerapan. Malang:
Muhammadiyah Malang.

Prayitno, E. (2006). Psikologi orang dewasa.Padang: Angkasa Raya

Prasetyo, B. (2014). Konsep diri pasien dengan pemasangan fiksasi eksternal di rso prof. Dr. R. Soeharso Surakarta.

Potter, P., \& Perry, A.G. (2009).Fundamental keperawatan.Edisi 7 buku 1 \& 2. Jakarta: Salemba Medika

Price, S. A., \& Wilson, L. M. (2006). Patofisiologi: Konsep Klinik ProsesProses Penyakit (6 ed.). (B. U. Pendit, Penerj.) Jakarta: EGC.

Purwaningsih, L.A.(2016). Respon adaptasi fisiologis dan psikologis pasien luka bakar yang diberikan kombinasi alternative moisture balance dressing dan seft terapi di rsup dr. Sardjito Yogyakarta.Vol 8 No. 1 Pebruari 2016

Rasjad, C. (2007). Pengantar Ilmu Bedah Orthopedi, Edisi 3 cetakan 5, Jakarta, Yarsif Watampone, ISBN 978-979-898046-6.

Rasmun. (2004). Stres, Koping Dan Adaptasi Teori Dan Pohon Masalah Keperawatan (Edisi 1). Jakarta : Sagung Seto.

Rachmaniah, D. 2012. Pengaruh Psikoedukasi Terhadap Kecemasan dan Kooping Orang Tua Dalam Merawat Anak Dengan Thalasemia Mayor Di RSU Kabupaten Tanggerang Banten.Tesis

Rajin M. 2012.Terapi Spiritual Emotional Freedom Technique (SEFT) Untuk Meningkatkan Kualitas Tidur Pasien Pasca Operasi di Rumah Sakit.Skripsi. Universitas Pesantren Darul Ulum. Jombang

Raudhoh, S. 2013. Psikoedukasi: Intervensi dan Rehabilitasi dan Prevensi. Artikel Penelitian. Magister Profesi Psikologi Universitas Padjadjaran. Serial online $\mathrm{http}: / /$ leapinstitute.com/learningmaterial/p sikoedukasiintervensi-rehabilitasi-danprevensi [diakses 24 Mei 2016]

Riyadina,et.all, (2009). Pola dan Determinan Sosiodemografi Cedera Akibat Kecelakaan Lalu Lintas di Indonesia. Majalah Kedokteran Indonesia, Volume: 59,Nomor: 10;464-472

Riyanto. 2011. Hubungan antara penambahan berat badan diantara dua waktu 
hemodialis (Interdialysis Weight Gain) terhadap kualitas hidup pasien penyakit ginjal kronik yang menjalani terapi hemodialisis di Unit Hemodialisis IP2K RSUP Fatmawati Jakarta. Diakses tanggal 12 Oktober 2014dari www.ui.ac.id.

Ruth A.Bryant.2006 Acute \& Chronic Wounds: Current Management Concepts. Third Edition.Mosby Elsevier. United States of America

Roy, S. C. (2009). The roy Adaptation Model (3rd ed.). Upper Saddle River: Pearson

Sadock, Benjamin James; Sadock, Virginia Alcott. (2007). Anxiety Disorder in : Kaplan \& Sadock's Synopsis of Psychiatry : Behavioral Sciences / Clinical Psychiatry, 10th Edition. New York: Lippincott Williams \& Wilkin. Hal 580

Sjamsuhidajat \& Long. (2005) Buku Ajar Ilmu Bedah(ed 2). Jakarta: EGC

Smeltzer, S. C., \& Bare, B. (2008). Brunner \& Suddarth's Textbook Of Medical Surgical Nursing. Philadelpia : Lippincott.

Smeltzer, S. C., \& Bare, B. (2006). Buku Ajar Keperawatan Medikal Bedah Brunner \& Suddarth (8 ed., Vol. III). (M. Ester, Penyunt., A. Hartono, H. Y. Kuncara, E. S. Siahaan, \& A. Waluyo, Penerj.) Jakarta: EGC

Soep. 2009. Pengaruh Intervensi Psikoedukasi Dalam Mengatasi Depresi Postpartum Di RSU. Dr. Pirngadi Medan. Tesis : Program Pascasarjana Universitas Sumatera Utara Medan. http://repository. usu.ac.id/bitstream/123456789/6885/1/0 9E01429.pdf [diakses 30 Mei 2016]

Stuart, Laria.(2005).Prinsip dan Praktek Keperawatan Psikiatri Ed.8.Jakarta EGC
Stuart, G. W. (2005). Principles and Practice of Psychiatric Nursing. (9th ed.). Canada: Mosby Elsevier

Stuart dan Sundeen, 2006.Buku Saku Keperawatan, Edisi 3. Jakarta : EGC

Supratiknya, A. (2011). Merancang Program Dan Modul Psikoedukasi. Edisi revisi. Jakarta: Universitas Sanata Dharma.

Susana dkk.(2007). Terapi modalitas dalam keperawatan jiwa.Yogyakarta : Mitra Cendikia Press Jogjakarta

Suratun. (2008). Seri Asuhan Keperawatan Klien Gangguan Sistem Muskuloskeletal. Jakarta: EGC.

Suriadi. 2007. Manajemen Luka. Romeo Grafika. Pontianak

Tomey, A.N. \& Alligood, M. R. (2006).Nursing Theoriest and Their Work. $7^{\text {th }}$ Ed. USA: Mosby Elsevier

Vaile, JH. (2013). AYear of Fractures: a snapshot analysis of the logistics, problems and outcomes of a hospitalbased fracture liaison service. Osteoporos Int (2013) 24:2619-2625

Videbeck, S. (2008).Buku ajar keperawatan jiwa.Jakarta : EGC

Waluyo, A., Mustikasari., Setiawan, A. (2014) Peningkatan Pengetahuan Dan Penurunan Tingkat Depresi Pasien Penyakit Ginjal Kronik Yang Menjalani Terapi Hemodialisa Dengan Terapi Psikoedukasi. Fakultas Ilmu Keperawatan Universitas Indonesia

Weine SM, Raina D, Zhubi M, Delesi M, Huseni D, Feetham S, et et al. (2005) . The Tafes Multi-Family Group Intervention For Kosovar Refugees: A Feasibility Study. Journal of Nervous and Mental Disease.100-107 